\title{
Stomatal Conductance Measurement for Toxicity Assessment in Zero-Effluent Constructed Wetlands: Effects of Landfill Leachate on Hydrophytes
}

\author{
Andrzej Białowiec ${ }^{1, *(\mathbb{D}}$, Jacek A. Koziel ${ }^{2}$ a and Piotr Manczarski $^{3}$ \\ 1 Faculty of Life Sciences and Technology, Wroclaw University of Environmental and Life Sciences, \\ 37a Chełmońskiego Str., 51-630 Wrocław, Poland \\ 2 Department of Agricultural and Biosystems Engineering, Iowa State University, Ames, IA 50011, USA; \\ koziel@iastate.edu \\ 3 Department of Environmental Engineering, Faculty of Building Services, Hydro and Environmental \\ Engineering, Warsaw University of Technology, 00-653 Warsaw, Poland; piotr.manczarski@pw.edu.pl \\ * Correspondence: andrzej.bialowiec@upwr.edu.pl; Tel.: +48-713-205-700
}

Received: 24 January 2019; Accepted: 1 February 2019; Published: 5 February 2019

\begin{abstract}
In this research, we explore for the first time the use of leaf stomatal conductance $\left(g_{s}\right)$ for phytotoxicity assessment. Plants respond to stress by regulating transpiration. Transpiration can be correlated with stomatal conductance when the water vapor pressure gradient for transpiration is constant. Thus, our working hypothesis was that the $g_{s}$ measurement could be a useful indicator of the effect of toxic compounds on plants. This lab-scale study aimed to test the measurement of $g_{s}$ as a phytotoxicity indicator. Our model plants were two common hydrophytes used in zero-effluent constructed wetlands for treating landfill leachate. The toxic influence of two types of leachate from old landfills (L1, L2) on common reed (Phragmites australis (Cav.) Trin. ex Steud.) and sweet flag (Acorus calamus L.) was tested. The gs measurements correlated well with plant response to treatments with six solutions ( 0 to $100 \%$ ) of landfill leachate. Sweet flag showed higher tolerance to leachate solutions compared to common reed. The estimated lowest effective concentration (LOEC) causing the toxic effect values for these leachates were $3.94 \%$ of L1 and $5.76 \%$ of L2 in the case of reed, and $8.51 \%$ of L1 and $10.44 \%$ of L2 in the case of sweet flag. Leachate L1 was more toxic than L2. The leaf stomatal conductance measurement can be conducted in vivo and in the field. The proposed approach provides a useful parameter for indicating plant responses to the presence of toxic factors in the environment.
\end{abstract}

Keywords: environmental pollution; remediation; landfill leachate; constructed wetlands; hydrophytes; leaf stomatal conductance; plants transpiration; LOEC; environmental analysis; environmental assessment

\section{Introduction}

Policy plans are being made to phase out the present day landfilling of municipal solid waste (MSW) with technologies consistent with the zero-waste, waste-to-carbon [1], and circular economy goals. However, even with the advances of the circular economy, the leachate of old, legacy landfills will need to be managed. One of the promising technologies for landfill leachate treatment and disposal is because of a considerable decrease in leachate volume due to evapotranspiration from zero-effluent constructed wetlands (CWs) [2-7]. Plants have a critical role in determining the dynamics of water loss, mainly by controlling the rate of water loss through evaporation and plant transpiration, i.e., evapotranspiration (ET). The ET of emergent hydrophytes (aquatic plants) in CWs is significant, reaching levels that are 7 8 times higher than actual evaporation without plants [7]. 
The leachate ET technology in zero-effluent CWs relies on evaporation from free water and soil surfaces and plant transpiration. An important CW design consideration is the toxic properties of leachate and the nutrients for improved plant growth conditions. With these eco-technologies for landfill leachate treatment, plants-typically hydrophytes-are exposed to leachate containing both nutrients and toxic compounds, e.g., ammonium and heavy metals. Hydrophyte response differs with soil and climatic conditions, which, in turn, influence the treatment efficiency related to ET. As ET is the main mechanism of leachate treatment, this parameter may also be used as an indicator of plant activity [8,9].

In this research, we explore for the first time the use of leaf stomatal conductance $\left(g_{s}\right)$, which is correlated to plant transpiration, to determine the toxic influence of harmful compounds in landfill leachate on plants. The advantages of the proposed measurement of $g_{s}$ as a toxicity indicator are that it is (1) less invasive to plants, (2) an easily measurable parameter, and (3) a measurement applicable to the on-site, field scale assessment of hydrophytes in CWs [10] and plants in general.

Therefore, we hypothesized that the direct measurement of leaf stomatal conductance might indicate a plant's response to toxic substances in the environment and that the stomatal conductance will decrease with the increase of toxicant concentration. The proposed new method allows observation of the effect of toxicants on plant activity without damaging the plants in vivo.

The aim of this initial lab-scale study was to determine the influence of potentially toxic substances in two types of landfill leachate on leaf stomatal conductance of two hydrophyte species and to present an innovative approach to using the measurement of leaf stomatal conductance as a phytotoxicity indicator.

\section{Materials and Methods}

\subsection{Landfill Leachate and Hydrophytes}

Landfill leachate originating from two MSW landfills were used in the experiment: (L1) from Zakurzewo, near Grudziadz, Poland; and (L2) for Wola Pawłowska, near Ciechanów, Poland. The detailed multicomponent and initial chemical and physical properties of the landfill leachates used in the experiment have been presented by Białowiec [9]. Two emergent hydrophyte species were used: common reed (Phragmites australis (Cav.) Trin. ex Steud and sweet flag (Acorus calamus L.). The average plant weight and length was $19.5 \pm 11.6 \mathrm{~g}$ and $42.1 \pm 11.2 \mathrm{~cm}$, and $34.2 \pm 16.9 \mathrm{~g}$ and $66.2 \pm 10.8 \mathrm{~cm}$ for P. australis and A. calamus, respectively.

\subsection{The Experimental Matrix}

The experiment was designed on two groupings of landfill leachate (L1, L2) and two plant species (P. australis, A. calamus). The independent variable was the concentration of landfill leachate in the solution; i.e., $0 \%$ (tap water), $6.25 \%, 12.5 \%, 25 \%, 50 \%$, and $100 \%$. Each variant of the experiment was repeated $\mathrm{n}=5$ times. The experimental matrix with 24 variants is shown in Table 1 . The measured leaf stomatal conductance $\left(g_{s}\right)$ was used as the dependent variable.

Table 1. Experimental design matrix variants.

\begin{tabular}{|c|c|c|c|c|c|c|c|}
\hline Plant Species & $\begin{array}{c}\text { Leachate } \\
\text { Type }\end{array}$ & \multicolumn{6}{|c|}{ Leachate Concentration (\%) } \\
\hline A. calamus & $\begin{array}{l}\text { L2 } \\
\text { L1 } \\
\text { L2 }\end{array}$ & 0 (tap water) & 6.25 & 12.5 & 25.0 & 50.0 & 100.0 \\
\hline
\end{tabular}

The plants were cultivated in $1.5 \mathrm{~L}$ bottles placed in boxes. Five bottles representing the same variant (replicates) were placed in one box, so each box represented one specified variant. The boxes were arranged in a greenhouse along the window and in accordance with experimental 
factors: P. australis-L1 0\%/100\%, L2 0\%/100\%; A. calamus-L1 0\%/100\%, L2 0\%/100\%; i.e., a total of 120 bottles arranged in 24 boxes (variants) with 5 replicates per box. To avoid any potential mistakes during measurements and data recording, the individual plants' spatial arrangement was not randomized. The greenhouse window length was $25 \mathrm{~m}$, which ensured that all plants had similar lighting conditions. The experiment was conducted at $25.4 \pm 6.1^{\circ} \mathrm{C}$. The greenhouse location was $53^{\prime} 74^{\prime \prime} \mathrm{N}$, and $20^{\prime} 44^{\prime \prime} \mathrm{E}$.

\subsection{Experimental Procedure}

The experimental procedures were similar to those described by Białowiec et al. [11]. Briefly, the plants were pre-cultivated in tap water for 4 weeks. After that, the 4-week-old plants were placed in bottles with solutions of landfill leachate (Table 2). The minimum 4-week duration of the plants' hydroponic exposure to leachate was used according to the previous experiments that were focused on the influence of landfill leachate on transpiration rate, which was measured gravimetrically $[8,9]$. Gravimetric measurements, while accurate, have a low potential to be used in field work. The leaf stomatal conductance measurement we advanced here is suited well for on-site field work. The water was topped up in each bottle weekly to the $\frac{3}{4}(1.125 \mathrm{~L})$ level. Only tap water (i.e., without leachate) was used to replenish water losses due to transpiration in both control and treatment.

Table 2. The timeline of the experiment.



* daily measurements of leaf stomatal conductance $\left(g_{s}\right)$ during week 8.

The leaf stomatal conductance $\left(g_{s}\right)$ was measured daily in week 4, i.e., after 3 weeks of leachate treatment, using an AP-4-UM-3 porometer (Delta-T Devices, Cambridge, UK). The porometer was calibrated before measurements using the direct calibration technique recommended by the manufacturer. The porometer was equipped with a molded polypropylene calibration plate with six groups of holes; the rate of diffusion of water vapor through these holes has been carefully verified. Water vapor was provided by backing the plate with dampened paper. The sensor head was clipped onto the calibration plate, and readings were stored from each of the six standard calibration positions. Calibrations and measurements followed a detailed description in the user manual [12].

The leaf stomatal conductance was measured for each plant. Five randomly selected locations on leaves (large enough to allow the proper placement of the porometer sensor) were selected each day. A total of 4200 measurements of $g_{s}$ were made, taking into consideration the 5 repetitions of the variant (box), 5 measurement locations on each plant, 2 plant species, 2 leachate typed, 6 leachate concentrations, and 7 days. The obtained data were incorporated into the subsequent statistical analyses as unweighted means for each plant, leachate type, and leachate dilution.

\subsection{Toxicity Evaluation-the Lowest Effective Concentration causing a Toxic Effect (LOEC)}

The inhibiting effect $(I)$ caused by landfill leachate solutions was calculated with:

$$
I=100 \frac{(C-T)}{C}
$$

where:

$I=$ effect caused by each landfill leachate solution $(\%)$;

$\mathrm{C}=$ mean measured leaf stomatal conductance for control treated with tap water only (mmol $\left.\mathrm{H}_{2} \mathrm{O} \cdot \mathrm{m}^{-2} \cdot \mathrm{s}^{-1}\right)$; 
$T=$ mean measured leaf stomatal conductance for plants treated with landfill leachate solutions (mmol $\left.\mathrm{H}_{2} \mathrm{O} \cdot \mathrm{m}^{-2} \cdot \mathrm{s}^{-1}\right)$.

The estimated $I$ were then examined in relation to leachate concentrations, and LOEC values were estimated using the following function:

$$
I=a_{1}-e^{\left(L O E C-a_{2} \cdot C_{r}\right)}
$$

where:

$C_{r}=$ landfill leachate solution concentration used in the experiment (\%);

$a_{1}(\%)$ and $a_{2}(-)=$ best fit constants [13].

The LOEC was therefore estimated through knowing the inhibition for a given leachate concentration and knowing that $a_{1}>I$ and $0<a_{2}<1$ from the transformed Equation (2):

$$
L O E C=\ln \left(a_{1}-I\right)+a_{2} \cdot C_{r}
$$

The best fit constants $a_{1}$, and $a_{2}$ were determined experimentally.

\subsection{Statistical Procedures}

The analysis of variance between mean values of estimated leaf stomatal conductance $\left(\mathrm{g}_{\mathrm{s}}\right)$ of P. australis-L1, P. australis-L2, A. calamus- $\mathrm{L} 1$, and A. calamus- $\mathrm{L} 2$ groups to indicate the influence of leachate concentration $(\mathrm{Cr}$ ) was carried out with the one-way ANOVA test (followed by post-hoc Tukey's test) at a significance level of $p<0.05$. The estimation of LOEC values was completed with non-linear regression and the calculation of the determination coefficient $R^{2}$. The Statistica 12.0 software package (Statsoft Polska, Kraków, Poland) was used.

\section{Results}

The measurements of $g_{s}$ confirmed the usefulness of this method for the observation of plant responses to toxicants in the environment. Plants responded by reducing the $g_{s}$ expressed in mmol $\mathrm{H}_{2} \mathrm{O} \cdot \mathrm{m}^{-2} \cdot \mathrm{s}^{-1}$ (Figure 1). In the case of reed, plants growing in the solution with an L1 concentration of $6.25 \%$ reduced $g_{s}$ by about $74 \%$ compared to tap water (Figure 1). Plants submerged in $6.25 \%$ solution of L2 reduced $g_{s}$ by about $56 \%$ in relation to control. Further increase of leachate content had no statistically significant influence on the measured changes in $g_{s}$. Reed response measured as $g_{s}$ was greater in the case of L1 than L2.

The measured leaf stomatal conductance was also capable of differentiating the response of sweet flag and reed for the same leachate type and concentration. The lower leachate content in the solution $(6.25 \%)$ had a positive and significant $(p<0.05)$ influence on the $g_{s}$ value (Figure 1 ) mostly due to the fertilization effect of nutrients present in the leachate under a relatively low content of toxicants. The further increase of leachate content caused successive decreases of $g_{s}$ until complete inhibition in the case of the raw leachate $(100 \%)$.

The plant's transpiration rate is correlated to leaf stomatal conductance. Therefore, the hypothesis that direct measurement of $g_{s}$ may indicate a plant's response to toxic factors was confirmed in this controlled environment. To better understand the observed phenomenon of toxic compound influence on a plants' stomatal conductance, more research should be done, including the influence of the lighting, the age of the plant, leaf development $[14,15]$, the plant physiological status and particularly plant water status, indicators of saline, and osmotic stress [16]. Additionally, more work should be done on any potential chemical transformation such as ammonification, nitrification, organics degradation, a plants' uptake in relation to a possible plant's survival mechanisms under exposure to a mixture of complex toxicants, and selected physiological interactions between root zone and leaf physiology. 

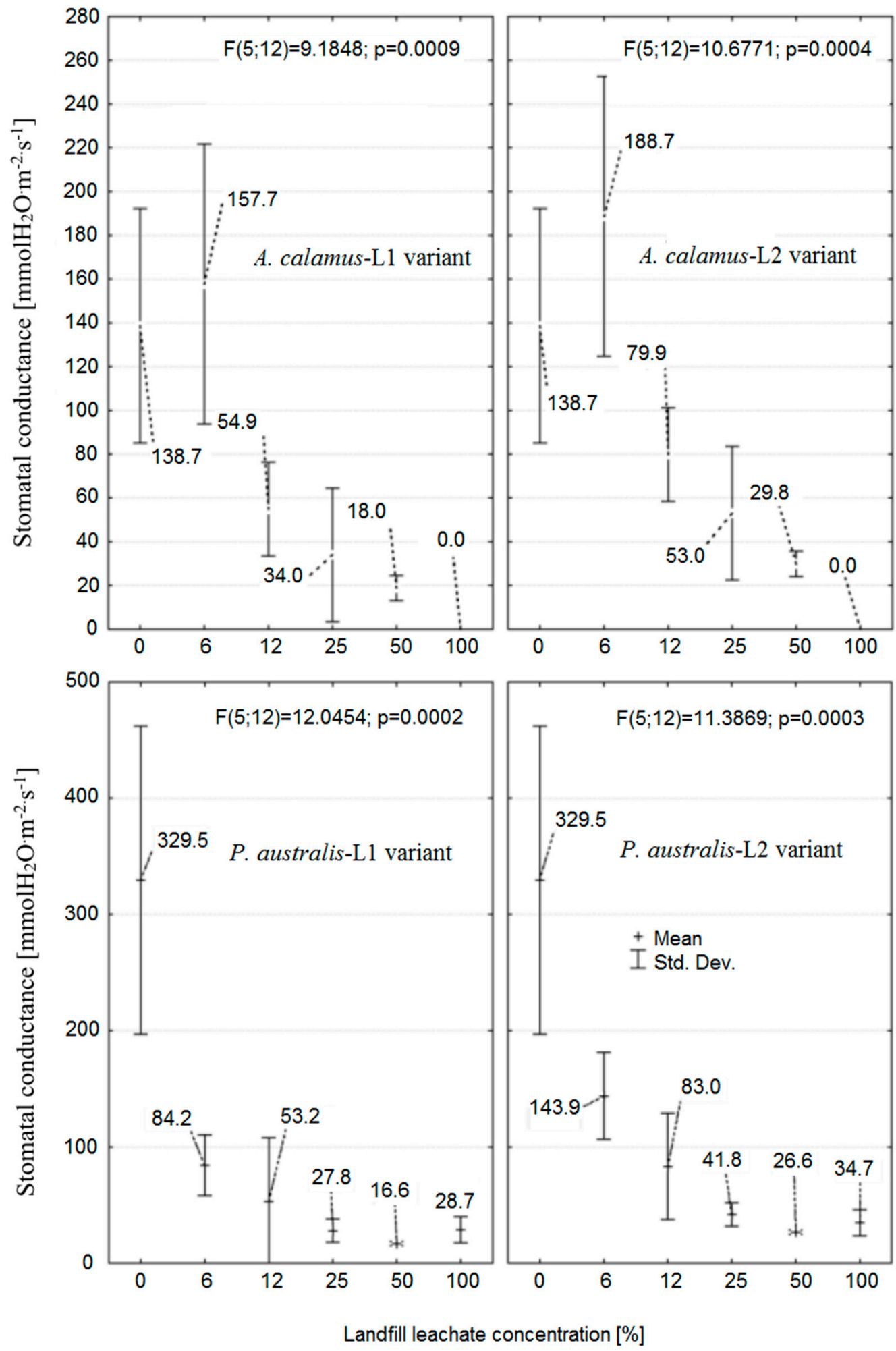

Figure 1. Measured mean ( \pm SD (standard deviation)) leaf stomatal conductance of sweet flag (Acorus calamus L.) in the upper part and reed (Phragmites australis (Cav.) Trin. ex Steud) in the lower part as a function of leachate concentration treatment. Plants were cultivated for 4 weeks in landfill leachate solutions L1 and L2 at six landfill leachate concentrations from 0 (control) to $100 \%$. The F-Snedecor statistic (F) and probability $(p)$ indicating the significance of the difference between mean values are given. 
The LOEC values of leachate L1 and L2 were estimated for both plant species. The coefficient of determination value was relatively high in the range of $\sim 0.782-0.846$ (Figure 2). L1 toxicity was higher than that of L2 (lower values of LOEC). LOEC values were higher in sweet flag than reed for both types of leachate. Reed LOEC values were between 3.94 and 5.76\% (Figure 1). Sweet flag values varied from 8.51 to $10.44 \%$, showing higher resistance than reed.

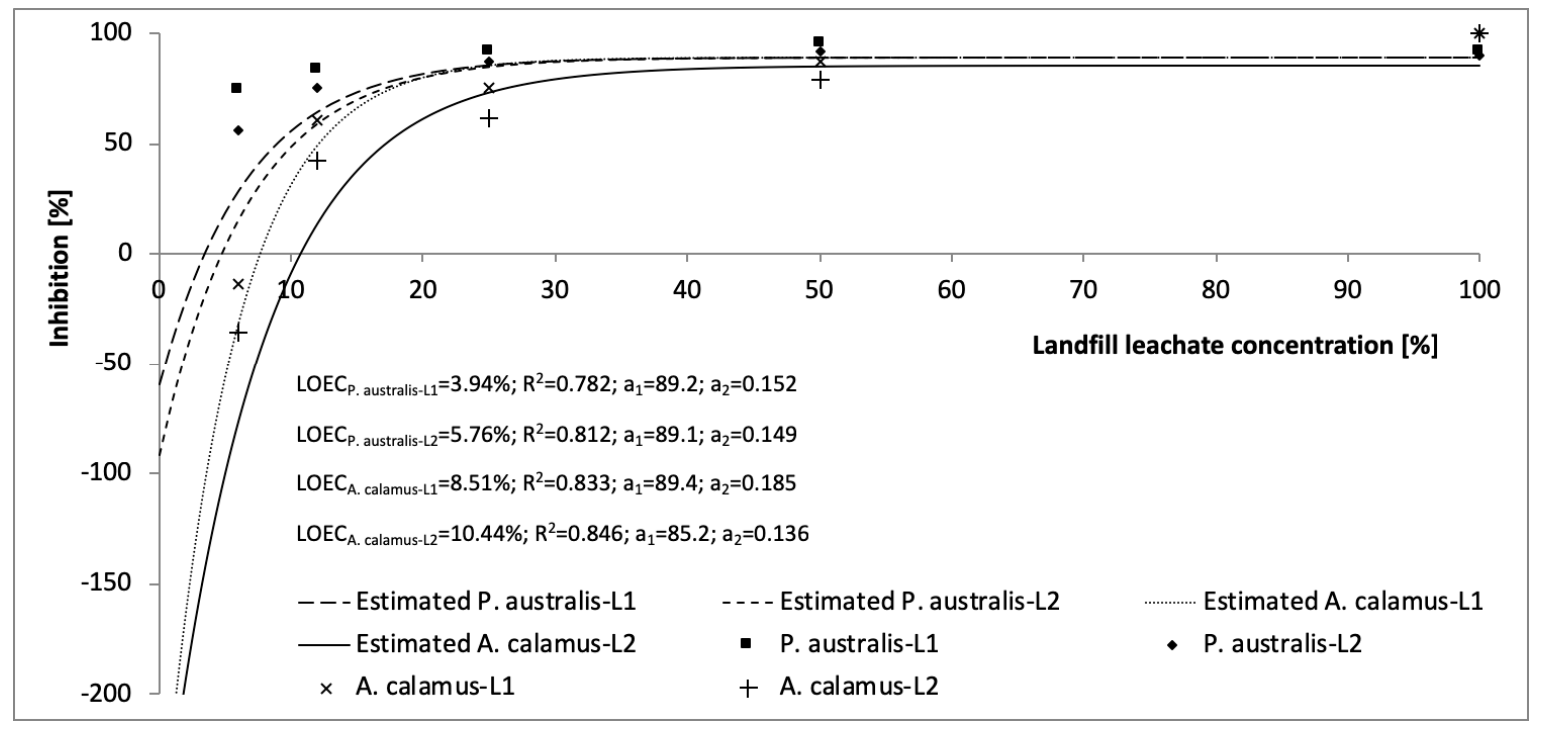

Figure 2. The estimation of lowest effective concentration causing the toxic effect (lowest effective concentration [LOEC]) values of landfill leachate L1 and L2, on leaf stomatal conductance of P. australis, and $A$. calamus; the $\mathrm{a}_{1}(\%)$ and $\mathrm{a}_{2}(-)=$ best-fit constants, $\mathrm{R}^{2}=$ determination coefficients.

\section{Conclusions}

The leaf stomatal conductance measurements were correlated with plant response to toxics in landfill leachate. Sweet flag was more resistant to landfill leachate treatment than reed. Based on these initial lab-scale studies, it is recommended that the leachate effluent content discharged into the zero-effluent constructed wetland system should not exceed $\sim 8-11 \%$ and $\sim 3-6 \%$ for sweet flag and reed, respectively, especially during the initial growth stage. The recommended landfill leachate dose rate could be adjusted to the local precipitation regime. Further research should be continued on the development and benchmarking of this method compared to other protocols. The pros of the proposed leaf stomatal conductance measurement warrant further research to develop it into a robust and minimally-invasive approach for measuring plant response to the presence of toxins in the environment.

Author Contributions: Conceptualization, A.B. and P.M.; methodology, A.B.; validation, A.B., J.A.K., and P.M.; investigation, A.B.; resources, A.B.; data curation, A.B. and P.M.; writing-original draft preparation, A.B.; writing-review and editing, A.B., P.M., and J.A.K.; visualization, A.B., and J.A.K.

Funding: This experimental work was completed with the financial support of the National Science Centre, Krakow, Poland, grant No. N3313/T02/2007/32. The publication is financed under the program of the Minister of Science and Higher Education "Strategy of Excellence-University of Research" in 2018-2019 project number 0019/SDU/2018/18 in the amount of PLN 700000.

Acknowledgments: The authors would like to thank the Fulbright Foundation for funding the project titled "Research on pollutants emission from Carbonized Refuse Derived Fuel into the environment", completed at the Iowa State University. In addition, this project was partially supported by the Iowa Agriculture and Home Economics Experiment Station, Ames, Iowa. Project no. IOW05556 (Future Challenges in Animal Production Systems: Seeking Solutions through Focused Facilitation) sponsored by Hatch Act and State of Iowa funds.

Conflicts of Interest: The authors declare no conflict of interest. 


\section{References}

1. Białowiec, A.; Micuda, M.; Koziel, J.A. Waste to carbon: Densification of torrefied refuse-derived fuels. Energies 2018, 11, 3233. [CrossRef]

2. Białowiec, A.; Wojnowska-Baryła, I.; Agopsowicz, M. The efficiency of evapotranspiration of landfill leachate in the soil-plant system with willow Salix amygdalina L. Ecol. Eng. 2007, 30, 356-361. [CrossRef]

3. Białowiec, A.; Albuquerque, A.; Randerson, P.F. The influence of evapotranspiration on vertical flow subsurface constructed wetland performance. Ecol. Eng. 2014, 67, 89-94. [CrossRef]

4. Gregersen, P.; Brix, H. Zero-discharge of nutrients and water in a willow dominated constructed wetland. Water Sci. Technol. 2001, 44, 407-412. [CrossRef] [PubMed]

5. Headley, T.R.; Davison, L.; Huett, D.O.; Muller, R. Evapotranspiration from subsurface horizontal flow wetlands planted with Phragmites australis in sub-tropical Australia. Water Res. 2012, 46, 345-354. [CrossRef] [PubMed]

6. O'Hogain, S.; McCarton, L.; Reid, A.; Turner, J. A review of zero discharge wastewater treatment systems using reed willow bed combinations in Ireland. Proceedings of 12th IWA International Conference on Wetland Systems for Water Pollution Control, Venice, Italy, 4-8 October 2010.

7. Shelef, O.; Gross, A.; Rachmilevitch, S. Role of plants in a constructed wetland: Current and new perspectives. Water 2013, 5, 405-419. [CrossRef]

8. Bialowiec, A.; Agopsowicz, M. Using phytotoxicological test for landfill leachate dose selection in willow short rotation plantations. In Proceedings of the Eleventh International Waste Management and Landfill Symposium in Sardinia, Santa Margherita di Pula, Italy, 1-5 October 2007.

9. Białowiec, A. Transpiration as landfill leachate phytotoxicity indicator. Waste Manag. 2015, 39, $189-196$. [CrossRef] [PubMed]

10. Białowiec, A.; Kasiński, S. Landfill leachate treatment in soil-plant systems-Possibilities of leachate dose rate selection in initial plants growth. Annu. Set Environ. Prot. 2009, 11, 1267-1278.

11. Bialowiec, A.; Randerson, P.F.; Kopik, M. Using fractal geometry to determine phytotoxicity of landfill leachate on willow. Chemosphere 2010, 79, 534-540. [CrossRef] [PubMed]

12. DELTA-T DEVICES. User Manual for the Porometer Type AP4. Available online: https:/ /www.delta-t.co. uk/wp-content/uploads/2017/02/AP4_Porometer_User_Manual_v3.1.pdf (accessed on 23 January 2019).

13. Bialowiec, A.; Randerson, P.F. Phytotoxicity of landfill leachate on willow-Salix amygdalina L. Waste Manag. 2010, 30, 1587-1593. [CrossRef] [PubMed]

14. Matsumoto, K.; Ohta, T.; Tanaka, T. Dependence of stomatal conductance on leaf chlorophyll concentration and meteorological variables. Agr. Forest Meteorol. 2005, 32, 44-57. [CrossRef]

15. Savvides, A.; Fanourakis, D.; Van Ieperen, W. Co-ordination of hydraulic and stomatal conductances across light qualities in cucumber leaves. J. Exp. Bot. 2012, 63, 1135-1143. [CrossRef] [PubMed]

16. Paz, R.C.; Reinoso, H.; Espasandin, F.D.; González Antivilo, F.A.; Sansberro, P.A.; Rocco, R.A.; Ruiz, O.A.; Menéndez, A.B. Alkaline, saline and mixed saline-alkaline stresses induce physiological and morpho-anatomical changes in Lotus tenuis shoots. Plant Biol. 2014, 16, 1042-1049. [CrossRef] [PubMed]

(C) 2019 by the authors. Licensee MDPI, Basel, Switzerland. This article is an open access article distributed under the terms and conditions of the Creative Commons Attribution (CC BY) license (http:// creativecommons.org/licenses/by/4.0/). 